\title{
Komparasi Perhitungan Kadet Secara Manual dan Dengan Menggunakan Program-Program Pelayaran Dalam Pelaksanaan Passage Plan
}

\author{
Samsul Huda ${ }^{a}$, Firdaus Sitepu ${ }^{b}$, Vitrianna Sulistyaningrum ${ }^{*}$, Gilang Pambudi Supar ${ }^{\text {d }}$ \\ a,b,c,d Politeknik Ilmu Pelayaran Semarang \\ aE-mail : samhud729@gmail.com \\ ${ }^{b}$ E-mail : firdaus.sitepu@yahoo.co.id \\ c*E-mail : vitriannas@pip-semarang.ac.id
}

\begin{abstract}
ABSTRAK
Untuk meningkatkan kemampuan akademis seorang kadet maka perlu sekali menerapkan prinsip-prinsip pelayaran dengan penggunaan teknologi komputer yang diakomodir dengan adanya program-program pelayaran yang sudah ada di atas kapal. Dalam pelaksanaan pelayaran selalu menggunakan passage plan atau perencanaan pelayaran untuk memudahkan dalam bernavigasi baik secara datar atau secara elektronik. Seorang kadet yang melaksanakan praktik memang harus benar-benar dibekali dengan kemampuan menghitung secara manual dan kemampuan memahami penggunaan tabel-tabel ilmu pelayaran serta dapat mengaplikasikan dalam suatu program-program komputer. Metode penelitian yang digunakan adalah deskriptif. Pengumpulan data dilakukan dengan perhitungan manual konsep Ilmu Pelayaran Datar dengan menggunakan peta mercator dan komparasi hasil perhitungan dengan program-program yang ada di atas kapal, observasi, wawancara terstruktur, studi dokumenter, dan riset kepustakaan. Tujuan dari penelitian ini adalah untuk mengetahui perbandingan hasil hitungan manual dan dengan menggunakan programprogram pelayaran yang dilakukan oleh kadet dalam pelaksanaan Passage Plan. Hasil penelitian menunjukkan bahwa kadet masih kurang memahami penerapan rumus-rumus hitung pelayaran pada proyeksi mercator chart atau peta mercator. Kadet dalam memasukkan data dalam suatu program masih salah dan kurang teliti sehingga akan berpengaruh terhadap penerapan passage plan.
\end{abstract}

Kata kunci : komparasi, program pelayaran, passage plan.

\begin{abstract}
To improve the academic ability of a cadet, it is necessary to apply the principles of shipping with the use of computer technology which is accommodated by existing shipping programs on board. In the implementation of a voyage, it always uses a passage plan to make it easier to navigate either flat or electronically. A cadet must really be equipped with the ability to calculate manually and the ability to understand the use of shipping tables and be able to apply it in a computer program. The research method is descriptive. Data collection was carried out by manual calculation of the concept of Flat Sailing using a Mercator map and comparison of the results of calculations with programs on the ship, observation, structured interviews, documentary studies and library research. The purpose of this study was to compare the results of manual calculations and by using shipping programs carried out by cadets in the implementation of the Passage Plan. The results showed that the cadets still did not understand the application of cruise calculation formulas on the projection of the mercator chart or mercator map. Cadets in entering data in a program are still wrong and less thorough so that it will affect the implementation of the passage plan.
\end{abstract}

Keywords : comparation, navigational pogram, passage plan. 


\section{PENDAHULUAN}

Tugas praktik laut bagi seorang kadet adalah wajib diselesaikan di atas kapal, banyak hal-hal tugas yang harus dilaksanakan dalam hal kompilasi antara teori dan praktik dengan berpedoman petunjuk dari buku tugas praktik laut atau dikenal dengan Training Record Book (TRB) Konvensi IMO STCW mensyaratkan bahwa dinas pelayaran kadet harus dicatat di dalam buku catatan pelatihan atau cadet record book yang telah disetujui oleh administrasi maritim yang bertanggung jawab untuk menerbitkan sertifikat kompetensi (International Chamber of Shipping, 2013). Para kadet ini bisa laki-laki dan juga perempuan (Kitada, 2021); (Kofoed \& McGovney, 2019). Sementara itu, tidak hanya di Indonesia, di banyak negara lain seperti Hong Kong, pada industri kelautan di dunia, penting untuk menjaga pendidikan tugas praktik laut secara komprehensif (Lau \& Ng, 2015).

Lingkungan pelatihan di atas kapal penting untuk kelangsungan karir kadet maritim atau kelautan dan untuk industri yang lebih luas (Lee et al, 2021). Seperti yang dilakukan dalam penelitian di Inggris yang menunjukkan bahwa kegiatan pembelajaran mendalam dalam simulasi maritim atau kelautan bersifat penting dan disarankan untuk meningkatkan tugas praktik (Jamil \& Bhuiyan, 2021). Salah satu tugas yang dilaksanakan oleh kadet adalah mempersiapkan "Passage Plan", dan ini sebagai contoh salah satu tugas dari buku tugas praktik laut. Passage plan juga adalah sebuah dimensi yang penting dalam pendekatan tes virtual (Sandvik et al, 2020). Perencanaan untuk kapal biasanya didukung oleh sistem rute cuaca (Li, Ringsberg, \& Rita, 2020). Passage planning perannya adalah untuk meningkatkan keselamatan dari navigasi (Kristic, Zuskin, Brcic, \& Valcic, 2020). Kemampuan seorang kadet akan teruji dengan pemahaman yang dilakukan, tentu kolaborasi pengetahuan teori yang diperoleh selama di kampus harus bisa diterapkan, dan penggunaan daftar ilmu pelayaran juga harus bisa diterapkan juga guna pembedaan hitungan manual dengan rumus serta hitungan penggunaan tabel-tabel yang tersedia yakni daftar ilmu pelayaran.

Kemampuan untuk menghitung manual dalam Ilmu Pelayaran Datar sangat penting untuk komparasi dalam program - program pelayaran yang ada di atas kapal. Misalnya, analisis akurasi posisi radar simulasi berkaitan dengan navigasi yang menandai validitas penghitungan dalam sebuah penelitian (Naus et al, 2021). Titik koordinat yang diperoleh ketika memplotkan posisi kapal sangat menentukan nilai keakuratan posisi kapal yang mana akan dikembangkan dan dicocokan dengan program-program pelayaran, yang mana program yang digunakan adalah bisa program Excel, atau program open CPN yang biasa digunakan di atas kapal. Dalam hal inilah yang menggarisbawahi bahwa penguasaan materi teori ketika di kampus harus benar- benar dikuasai dengan baik. Oleh karenanya peneliti memberikan bimbingan detail dari teori, rumus, perhitungan manual sampai dengan komparasi dengan programprogram yang ada. Sehingga harapannya seorang kadet harus tahu tentang penerapan passage plan yang baik dan benar. Dari penjelasan pendahuluan di atas, maka peneliti tertarik untuk membuat penelitian dengan berdasarkan pada prinsip-prinsip ilmu pelayaran yang dapat dibuktikan secara hitungan manual maupun dengan program-program yang ada dalam pelaksanaan penerapan passage plan.

\section{METODE}

Penulis menggunakan metode deskriptif dalam penelitian ini. Penulis juga melakukan survei kepada kadet, yakni penyelidikan yang diadakan untuk memperoleh fakta-fakta dari gejalagejala yang ada dan mencari keteranganketerangan secara faktual. 
Metode deskriptif berkesinambungan yang peneliti lakukan di kapal yakni peneliti terus-menerus mengobservasi atas fenomena-fenomena yang terjadi ketika kadet akan mengaplikasikan program-program pelayaran dalam penerapan ilmu pelayaran untuk menghitungnya.

Studi kasus dapat peneliti lakukan dengan melihat hal-hal di lapangan artinya bahwa penerapan ilmu pelayaran dapat secara benar diterapkan ke dalam program-program pelayaran sehingga penerapannya ketika dibandingkan dengan manual tidak terjadi perbedaan yang signifikan.

Observasi penelitian yang peneliti lakukan adalah dengan penelitian langsung terhadap kegiatankegiatan praktik di atas kapal yang dilaksanakan oleh seorang kadet dan mereka mampu mengaplikasikan program-program sederhana seperti program-program pelayaran yang sangat mudah membantu dalam penerapan perhitungannya sekaligus mempermudah pekerjaan ketika melaksanakan passage plan.

Peneliti akan melakukan penelusuran data historis obyek penelitian serta melihat sejauh mana proses yang berjalan telah terdokumentasikan dengan baik. Dokumen yang dapat peneliti gunakan adalah berupa catatan atau check list atau dokumen lainnya yang berkaitan dengan penerapan ilmu pelayaran seperti hasil perhitungan ke dalam passage plan.

\section{HASIL DAN PEMBAHASAN Haluan Utara Selatan}

Kapal bertolak dari $22^{\circ} 00^{\prime} \mathrm{S} /$ $112^{\circ} 00^{\prime} \mathrm{E}$ menuju $12^{\circ} 00^{\prime} \mathrm{S} / 112^{\circ} 00^{\prime} \mathrm{E}$, Berapakah arah haluan dan jarak tempuh kapal?

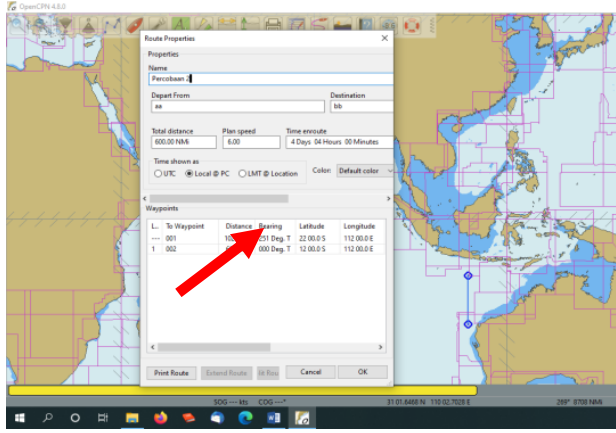

Gambar 1. Screenshoot Open CPN 4.8.0 Haluan Utara Sejati

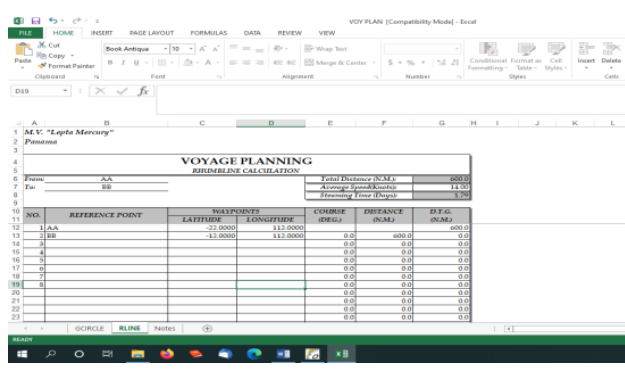

Gambar 2. Screenshoot Hasil Perhitungan Voyage Plan

Hitungan manual:

Tempat Tolak AA : $22^{\circ} 00^{\prime} \mathrm{S} /$ $112^{\circ} 00^{\prime} \mathrm{E}$

Tempat Tiba BB : $12^{\circ} 00^{\prime} \mathrm{S} /$ $112^{\circ} 00^{\prime} \mathrm{E}$

$\Delta \mathrm{Lt}=10^{\circ} 00^{\prime}$

Jauh $=10^{\circ} 00^{\prime} \times 60=600$ nautical mil

Haluan Utara sejati

Dengan program Nautical

Calculator

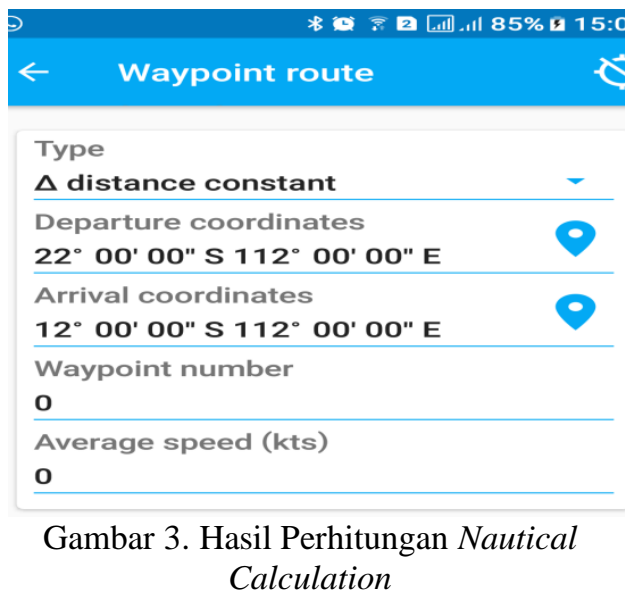




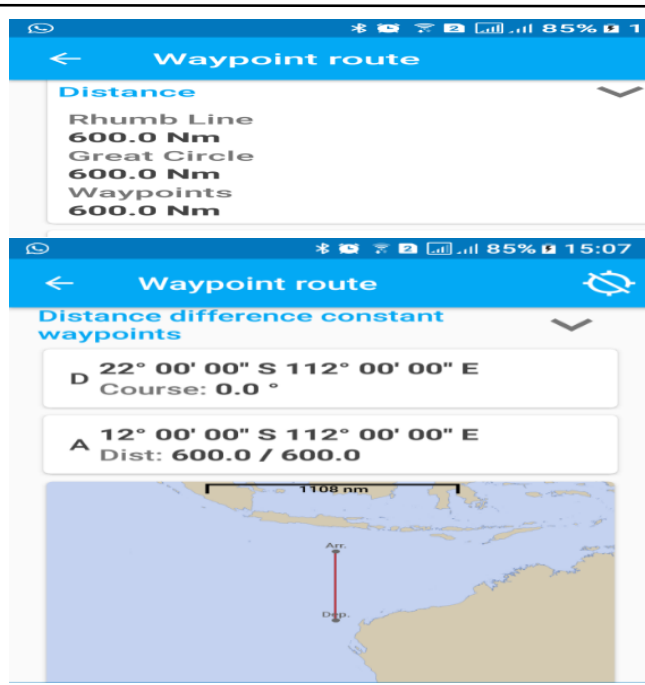

Gambar 4. Hasil Perhitungan Nautical Calculation

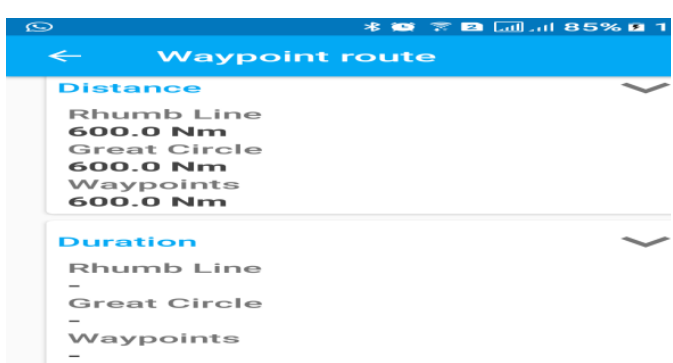

Gambar 5. Hasil Perolehan Jarak dari Nautical Calculation

\section{Haluan Serong}

Kapal bertolak dari $42^{\circ} 45^{\prime}$ N / $038^{\circ} 00^{\prime} \mathrm{W}$ menuju 27०30' $\mathrm{N} /$ $056^{\circ} 15^{\prime} \mathrm{W}$,

Berapakah arah haluan dan jarak tempuh kapal?

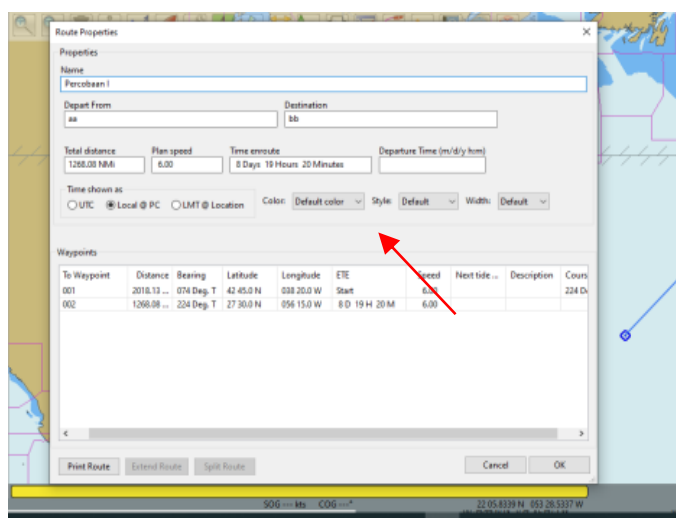

Gambar 6. Screenshoot Open CPN 4.8.0 Haluan Serong

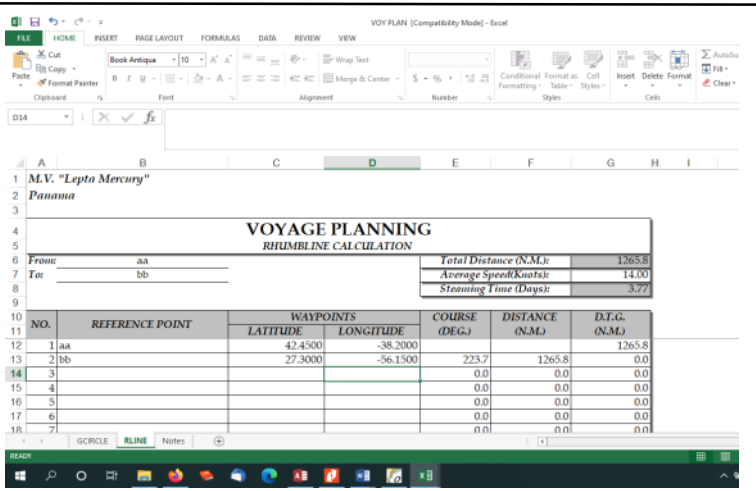

Gambar 7. Screenshoot Hasil Perhitungan Voyage Plan

\section{Haluan Rangkai dalam Suatu "Passage Plan"}

Kapal bertolak dari Taiwan menuju ke Jepang dengan detail voyage plan sebagai berikut:

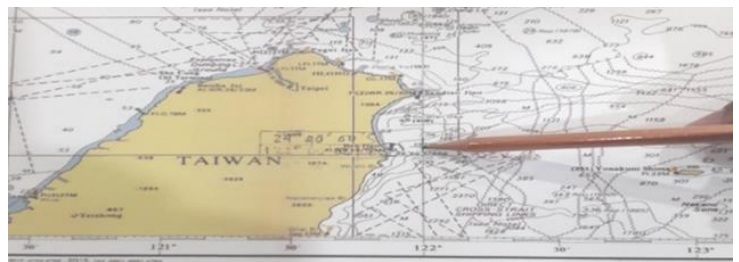

Gambar 8. Way Point 0 : Su Ou Gang

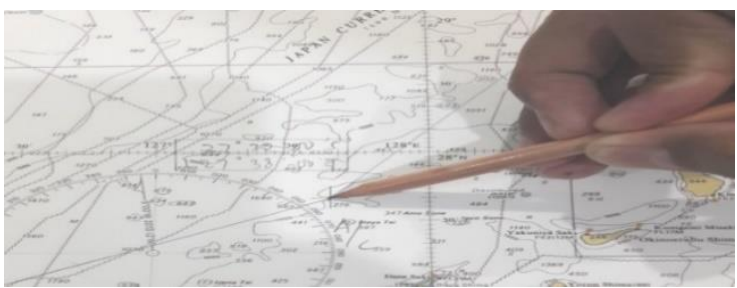

Gambar 9. Way Point 1 : Amami Gunto

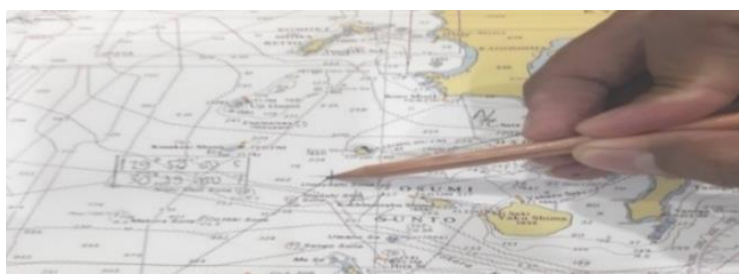

Gambar 10. Way Point 2 : Osumi Gunto

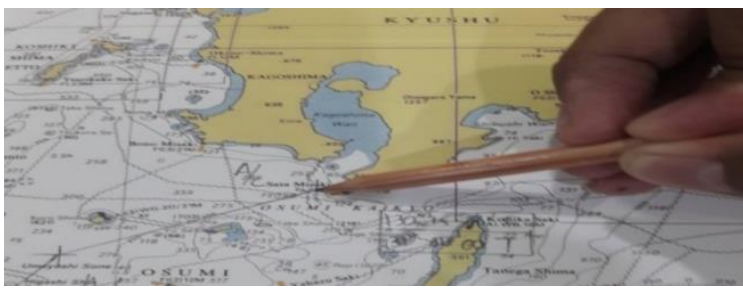

Gambar 11. Way Point 3 :Osumi Kaikyo 


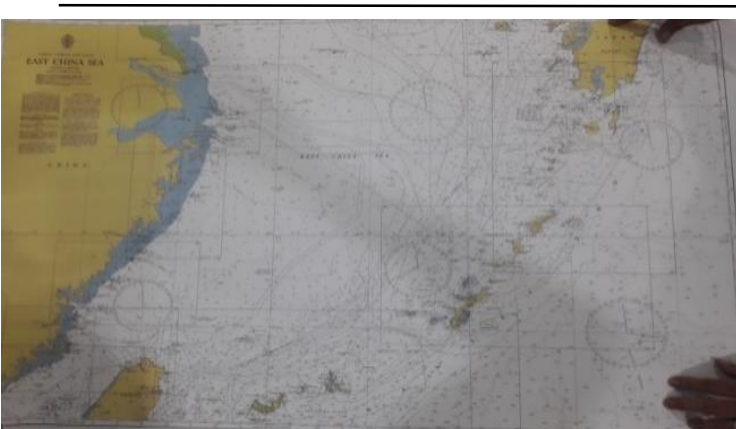

Gambar 12. Passage Plan Taiwan to Japan

\section{Passage Plan Taiwan to Japan}

Voyage/ Charter/ Project : 001/PIP/2020

From : Taiwan To : Japan

Estimated Speed : $10-15 \mathrm{kts}$

Date Commenced : 19/10/2020

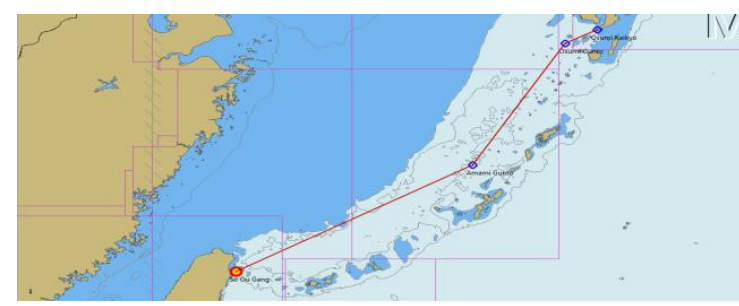

Gambar 13. Active Route on CPN 4.8.0 Program Taiwan to Japan

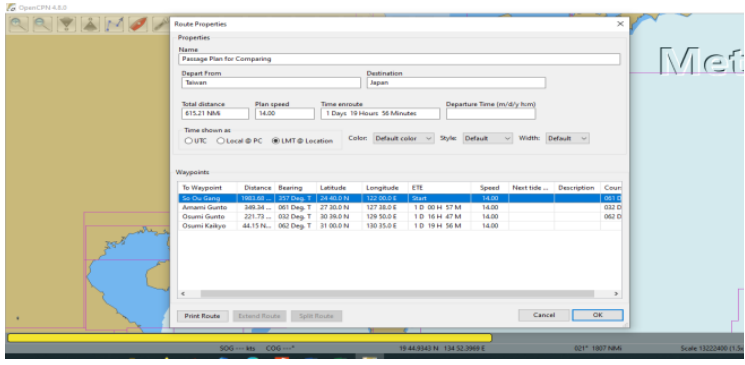

Gambar 14. View Result Active Route on CPN 4.8.0 Program Taiwan to Japan

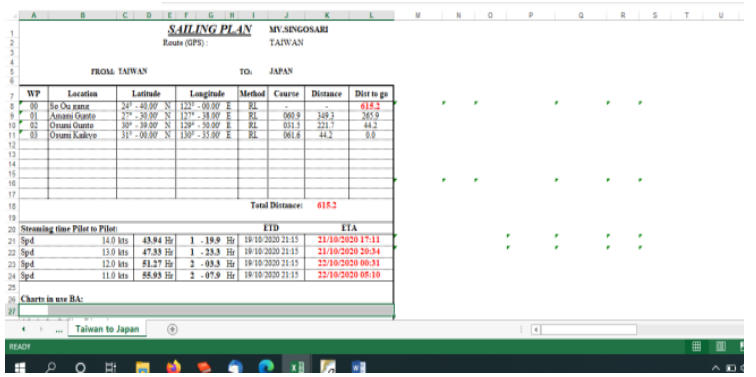

Gambar 15. Hasil Perhitungan dengan Program Excel

\section{Pembuktian Manual}

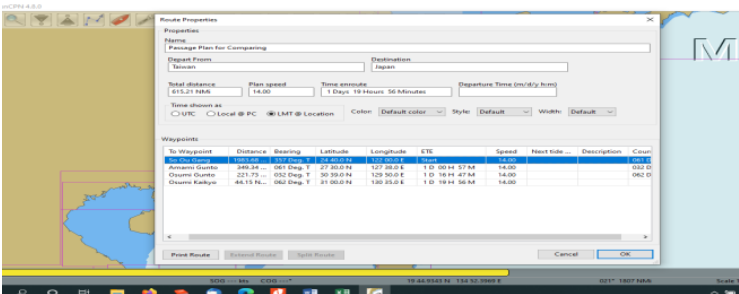

Gambar 16. Hasil Perhitungan dengan Program Komputer

\begin{tabular}{|l|l|l|c|c|}
\hline 00. & $24^{\circ} 40,000^{\prime} \mathrm{N}$ & $122^{\circ} 00,000^{\prime} \mathrm{E}$ & - & - \\
\hline 01. & $27^{\circ} 30,000^{\prime} \mathrm{N}$ & $127^{\circ} 38,000^{\prime} \mathrm{E}$ & 060.9 & 349.3 \\
\hline
\end{tabular}

So Ou Gang: $24^{\circ} 40,000^{\prime} \mathrm{N} / 122^{\circ} 00,000^{\prime} \mathrm{E}$ Amami Gunto: $27^{\circ} 30,000^{\prime} \mathrm{N} / 127^{\circ} 38,000^{\prime} \mathrm{E}$ $\Delta \mathrm{Lt}: 02^{\circ} 50.0^{\prime} \quad / \quad \Delta \mathrm{Bu}: 005^{\circ} 38.0^{\prime}$

$\operatorname{Tg} \mathrm{H}=\operatorname{Simp} / \Delta \mathrm{Lt}$

$=\Delta \mathrm{Bu} \times \operatorname{Cos} \mathrm{Ltm} / \Delta \mathrm{Lt}$

$=005^{\circ} 38.0^{\prime} \times \operatorname{Cos}($ Lt.tolak $+1 / 2 \Delta \mathrm{Lt}) / \Delta$

$\mathrm{Lt}$ $02^{\circ} 50$.

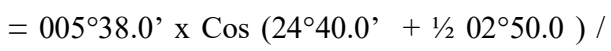

$=005^{\circ} 38.0^{\prime} \times \operatorname{Cos}\left(26^{\circ} 05.0^{\prime}\right) / 02^{\circ} 50.0$

$=005^{\circ} 38.0^{\prime} \times 0.898156 / 02^{\circ} 50.0$

$=338 \times 0.898156 / 170$

$=303.58 / 170$

$\mathrm{Tg} \mathrm{H}=1.78575=60.75168$

$\mathrm{H}=60^{\circ} 45.1^{\prime}=60.85====60.9$

Mencari Jauh

Jauh $=\Delta \mathrm{Lt} X \mathrm{Xg} \mathrm{H} \times$ Cosec $\mathrm{H}$

$60^{\circ} 45.1^{\prime}$

$$
=02^{\circ} 50.0 \times \operatorname{Tg} 60^{\circ} 45.1^{\prime} \times \text { Cosec }
$$

$=170^{\circ} \times 1.78575 \times 1 / \operatorname{Sin} 60^{\circ} 45.1^{\prime}$

$=170 \circ \times 1.78575 \times 1 / 0.87292$

$=170 \times \mathrm{x} 1.78575 \times 1.14558$

$=348.45977=====349.0 \mathrm{mil}$

Penggunaan Daftar Ilmu Pelayaran

1. Harus melihat haluan dan jauh

2. Komparasikan hasil delta lintang dan simpangnya

\section{SIMPULAN}

Dari hasil penelitian komparasi bersama tim, maka dapat disimpulkan bahwa seorang kadet atau taruna yang melaksanakan praktik masih kurang memahami penerapan rumus-rumus hitung pelayaran pada proyeksi mercator chart atau peta mercator sehingga belum 
bisa tepat ketika dibandingkan dengan hasil dari program-program pelayaran yang digunakan dalam passage plan.

Kadet atau taruna yang melaksanakan praktik dalam memasukkan data dalam suatu program masih kurang memahami dengan baik atau dengan kata lain masih salah dan kurang teliti sehingga akan berpengaruh terhadap penerapan passage plan.

Berdasarkan simpulan di atas, peneliti memberikan saran sebagai berikut. Kemampuan menghitung secara manual dengan menguasai konsep dasar ilmu pelayaran sangat diperlukan sekali bagi seorang kadet atau taruna yang akan melaksanakan praktik berlayar agar dalam masa praktiknya tersebut benarbenar sudah mengetahui, memahami dan mampu menerapkan dengan baik dalam pelaksanaan passage plan.

Perlu penguasaan teknologi komputer terkini atau dengan kata lain bahwa dengan perkembangan teknologi saat ini seorang kadet harus menguasai dengan baik dengan dibarengi juga kemampuan dasar teorinya, kemampuan konsepnya dan kemampuan pengembangannya yang juga didukung oleh para pengajar di masing-masing UPT diklat yakni dengan memberikan bimbingan-bimbingan dan ekstrakokurikuler "Navigation Modern"

\section{DAFTAR PUSTAKA}

International Chamber of Shipping. (2013). On Board Training Record Book for Officers in Charge of an Engineering Watch (Engine Cadets). Marisec.

Jamil, M. G., \& Bhuiyan, Z. (2021). Deep learning elements in maritime simulation programmes: a pedagogical exploration of learner experiences. International Journal of Educational Technology in Higher Education volume 18(18).
Kitada, M. (2021). Women Seafarers: An Analysis of Barriers to Their Employment. In Gekara V.O., Sampson H. (eds), The World of the Seafarer. WMU Studies in Maritime Affairs, vol 9. Springer, Cham. Springer.

Kofoed, M. S., \& McGovney, E. (2019). The Effect of Same-Gender or Same-Race Role Models on Occupation Choice: Evidence from Randomly Assigned Mentors at West Point. J. Human Resources Vol. 54, 430-467.

Kristic, M., Zuskin, S., Brcic, D., \& Valcic, S. (2020). Zone of Confidence Impact on Cross Track Limit Determination in ECDIS Passage Planning. Journal of Marine Schince and Engineering 8(8): 566.

Lau, Y.-y., \& Ng, A. K. (2015). The motivations and expectations of students pursuing maritime education. WMU Journal of Maritime Affairs, Vol. 14, 313331.

Lee, J., Dhesi, S., Phillips, I., Jeong, M., \& Lee, C. (2021). Korean Maritime Cadets' Onboard Training Environment Survey. Sustainability, Vol. 13(8).

Li, Z., Ringsberg, J. W., \& Rita, F. (2020). A voyage planning tool for ships sailing between Europe and Asia via the Arctic. Ships and Offshore Structures, Vol. 15, S10-S19.

Naus, K., Waz, M., Szymak, P., Gucma, L., \& Gucma, M. (2021). Assessment of ship position estimation accuracy based on radar navigation mark echoes identified in an Electronic 
Navigational

Chart.

Measurement, Vol. 169.

Sandvik, E., Nielsen, J. B., Asbjornslett, B. E., Pedersen, E., \& Fagerholt, K. (2020). Operational sea passage scenario generation for virtual testing of ships using an optimization for simulation approach. Journal of Marine Science and Technology. 